GÜNTHER, Klaus: "Amenazas a la libertad individual en el derecho penal ilustrado".

Polít. Crim. Vol. 16, No 31 (Junio 2021), Doc. 1, pp. 437-455.

[http://politcrim.com/wp-content/uploads/2021/07/Vol16N31D1.pdf]

\title{
Amenazas a la libertad individual en el derecho penal ilustrado*
}

\section{(Threatened) Individual Freedoms in Enlightened Criminal Law - What Freedoms?}

\author{
Klaus Günther \\ Doctor en Derecho. Profesor de teoría del Derecho, Derecho penal y Derecho procesal \\ penal en la Goethe-Universität Frankfurt am Main. \\ k.guenther@jur.uni-frankfurt.de
}

\section{Resumen}

Fecha de recepción: 01/03/2021. Fecha de aceptación: 18/03/2021.

El artículo analiza el desarrollo conceptual que ha tenido la idea de libertad dentro del Derecho penal. Entendida en sus primeras formulaciones como objeto de protección y como fundamento para participar en los procesos democráticos de confección de la ley penal, su valoración ha mutado a través del tiempo, respondiendo a las condiciones sociales e históricas en las que se desenvuelve. Apartándose de las concepciones más abstractas del individualismo normativo, se afirma que, en función de la mayor complejidad de las modernas sociedades capitalistas, la libertad individual encuentra una dependencia más intensa de las condiciones sociales y colectivas. El incremento de la complejidad y la diferenciación funcional de los sistemas sociales conducen a una considerable expansión de las libertades. Eso puede ser observado como un riesgo, aumentando así la experiencia de vulnerabilidad del individuo y, con ello, la demanda por mayor seguridad. Existe un aumento de la individualización y, al mismo tiempo, una dependencia del medio social. En este escenario, en un objeto más importante de protección penal se transforma la seguridad de la forma de vida que garantiza la producción y reproducción de las condiciones sociales de las que depende el individuo en lugar de la libertad como tal.

Palabras clave: política criminal, vulnerabilidad, forma de vida, legislación democrática, derechos de libertad

\begin{abstract}
This paper analyses the conceptual development of the idea of freedom within criminal law. Understood in its first formulations as an object of protection and as a basis for participation in the democratic processes of criminal law-making, its status has mutated over time, reflecting the social and historical conditions in which it operates. By departing from the more abstract conceptions of normative individualism, this paper argues that, due to the greater complexity of modern capitalist societies, individual freedom is more intensely dependent on social and collective conditions. The higher complexity and functional

\footnotetext{
* Artículo originalmente publicado en: Kritische Justiz 49, 2016/4, pp. 520-534, bajo el título: (Bedrohte) individuelle Freiheiten im aufgeklärten Strafrecht - Welche Freiheiten? Traducción por Francisco Acosta Joerges, LLM. Doctorando en derecho en la Goethe-Universität Frankfurt am Main. Becario CONICYTDAAD. Resumen del texto redactado por el traductor con la autorización del autor.
} 
differentiation of social systems lead to a considerable expansion of freedoms. This can be seen as a risk, thus raising the individual's experience of vulnerability and, thus, the demand for more security. There is an increase in individualisation and, at the same time, a dependence on the social environment. In this scenario, the security of the form of life that guarantees the production and reproduction of the social conditions on which the individual depends is transformed into a more important object of criminal protection instead of freedom as such.

Keywords: criminal law politics, vulnerability, form of life, democratic legislation, freedom rights.

1.

El Derecho penal ilustrado comienza en el Siglo de las Luces. En 1763 Voltaire critica duramente el Derecho y el proceso penal vigente. Con ocasión del famoso caso Calas, rechaza la instrumentalización del Derecho en favor del fanatismo religioso patrocinado por el Estado, violando así los derechos elementales del acusado. En 1764 se publica "De los delitos y las penas" de Beccaria. En dicha obra se aboga por un derecho penal preventivo, de carácter racional y proporcional, que apunta contra la pena de muerte, la tortura y, en general, contra un retribucionismo irracional, que solo aumenta el sufrimiento ya causado por el delito. Para ambos autores, el derecho de libertad individual es una de las premisas de su crítica al derecho penal.

En el caso de Voltaire, tal derecho se encarna en la libertad de conciencia y en la separación entre Derecho penal y religión. Adopta así también la forma de reconocimiento del individuo como objeto de un proceso penal definido exclusivamente por las normas legales. En el caso de Beccaria, se trata de la figura moderna del contrato social. A través de este se legitima tanto el establecimiento del Estado como del castigo penal. Ambos se justifican mediante el consentimiento voluntario de todas las partes contratantes respecto de las restricciones a la libertad que estipulan en el acuerdo. Las dos posiciones se mueven, en consecuencia, en un contexto de principios y argumentos donde la libertad individual, en forma de un derecho (subjetivo) de naturaleza general e igual para todas las personas, actúa como punto arquimédico.

Lo anterior puede aplicarse también a Kant. En 1797, es decir, en la última fase de la Ilustración, se opone críticamente al Derecho penal preventivo de Beccaria y defiende la pena de muerte desde una perspectiva retribucionista. ${ }^{1}$ Sin embargo, la importancia del derecho de la libertad es en él aún más claro que en sus predecesores. Para él, un derecho igualitario a la libertad es la encarnación del derecho por antonomasia: "La libertad (la independencia con respecto al arbitrio constrictivo de otro), en la medida en que puede coexistir con la libertad de cualquier otra según una ley universal, es este derecho único, originario, que corresponde a todo hombre en virtud de su humanidad." [Kant, Rechtslehre, B 237] Un Derecho penal preventivo, de carácter racional y proporcional, basado en el derecho de libertad y en un derecho de retribución, que reconozca la libertad, funcionan sobre la misma premisa (aunque Kant lo niegue con vehemencia). Esto se aplica con mayor razón a

\footnotetext{
${ }^{1}$ KANT (1975), p. 457. Las referencias a Kant en español pueden consultarse en: Kant (2008), passim.
} 
Feuerbach. En su manual de 1801 reúne el conjunto argumentos de sus predecesores y concibe un Derecho penal preventivo limitado a la protección de derechos subjetivos, principalmente, el derecho de libertad. La protección de este derecho — en un sentido penal a través de la coacción psicológica legalmente determinada - es la razón de ser del Estado. $\mathrm{Al}$ respecto, el $\S 9$ de su Manual señala: "El propósito de esta es establecer un estado jurídico [eines rechtlichen Zustandes] que proteja la libertad recíproca de todos".

\section{2.}

En esta tradición, moldeada y reformada por Hobbes, Locke, Kant y otros autores, la libertad individual como derecho general e igualitario está protegida de tres maneras por el Derecho penal: primero, a través de una autoridad política legislativa legitimada por el consentimiento de todos, ya sea por el contrato social o por la razón. En el ideal republicano democrático son los propios ciudadanos quienes, por intermedio de leyes, se dan a sí mismos un Derecho penal o quienes establecen una determinada autoridad legislativa —el parlamento-.

Segundo, la autoridad legislativa solo puede amenazar con la irrogación de una pena siempre y cuando esté establecida por ley. Es decir, debe vincularse como consecuencia jurídica a un determinado supuesto de hecho prestablecido legalmente, de carácter general y abstracto. El poder punitivo del Estado está sujeto a esta ley, tanto en la persecución penal como en la punición. No pueden invocarse ni los supuestos de hecho ni aplicarse las consecuencias jurídicas por parte de la autoridad penal de Estado retroactivamente.

Tercero, el Derecho penal establecido por ley no debe imposibilitar el fin en virtud del cual fue constituido: la protección del derecho de libertad con carácter general e igualitario. El medio para restringir las libertades penales y procesal-penales debe restringirse al mínimo necesario para la realización de aquel fin.

La protección de la libertad a través del Derecho penal significa entonces: por un lado, una protección directa de la libertad mediante la amenaza de irrogación de una pena, o bien, la imposición de un castigo por la lesión de la libertad, por parte del soberano que diseña y ejecuta las leyes. Por otro lado, significa una protección indirecta de la libertad en el sentido de que la protección penal debe adoptar la forma de una ley general y determinada que proteja la libertad y garantice la previsibilidad del castigo. Pero se trata de una protección indirecta también debido a otra razón: los propios titulares de los derechos de libertad elaboran las leyes penales y adoptan así la perspectiva de los afectados por las restricciones de la justicia penal a la libertad, a fin de preservar simultáneamente el mayor grado posible de igualdad de derechos de libertad (principio de ultima ratio, prioridad de alternativas no penales que respetan la libertad en mayor medida).

Por lo tanto, la protección de la libertad a través del Derecho penal estatal (protección de la libertad a través del Estado) siempre va de la mano de la protección de la libertad a través de un Derecho penal determinado por ley, a saber, un Derecho penal democrático-republicano

\footnotetext{
${ }^{2}$ FEUERBACH (1801), p. 12.
} 
(y parlamentario) que protege la libertad frente a las consecuencias destructivas de una usurpación ilegítima y arbitraria del poder punitivo por el propio Estado.

Pero ¿por qué se necesita el Derecho penal para proteger la libertad? La respuesta requiere mirar hacia atrás. La razón radica en la posición prominente que la libertad tiene en la moderna Europa Occidental y Central. En la tríada de derechos que se convirtió en decisiva para la Revolución Francesa de 1789, ocupa la libertad la primera ubicación: "Liberté, Egalité, Fraternité." (Lo mismo vale para la Revolución estadounidense). La mayoría de las veces esto ha sido interpretado en términos de libertad negativa, es decir, como ausencia de restricciones estatales a la libertad de acción individual. En un primer momento se aplica al caso de la libertad religiosa, pero luego a la libertad económica, especialmente desde finales del siglo XVIII y durante el XIX. Pero una comprensión positiva de la libertad, entendida como poder o capacidad de actuar, es fundamental tanto para la libertad de conciencia como para la autonomía privada (y para todas las demás libertades). Esto se conoce como agencia.

Como lo expresó Kant, ser libre significa, ante todo, ser su propio amo (sui iuris). No significa ser un esclavo, un sirviente ni depender de otro en toda su persona. Por un lado, esto se refiere a la tradición republicana que busca entender la libertad como dominio (dominium). Esta tradición se extiende desde Aristóteles a Cicerón, pasando por Maquiavelo y otros autores. ${ }^{3}$ Por otro lado, expresa la experiencia formativa de naturaleza moderna según la cual la libertad significa poder efectuar un comienzo [einen Anfang machen können]. Este nuevo comienzo hace una diferencia en el mundo, modifica las circunstancias, pero tiene su origen única y exclusivamente en la persona del agente. Solo por esta razón puede atribuírsele la acción. Al considerar ambos momentos, la libertad se manifiesta en tener una voz propia y en ser capaz de hacer algo responsablemente con ella. Se trata de un individualismo normativo, a partir del cual los individuos libres y responsables se constituyen y reconocen normativamente como sujetos de sus declaraciones y acciones (y consecuencias). ${ }^{4}$

Si se acepta esta concepción de libertad se vuelve evidente aquello que es punible: hacerse dueño de otro mediante una vulneración de derechos; someter a otro a su propio dominio como un esclavo, esto es, sin respetarlo como una persona cuya voluntad es vinculante porque es libre y no porque se ha expresado mediante amenazas, fuerza o engaño. Así, la voz propia de la otra persona es sustraída, se le quita su significado o se transforma en un medio para los fines de su amo. Lo anterior, sin embargo, no solo debe observarse en la relación individual entre autor y víctima, sino que, al mismo tiempo, debe observarse como un ataque al derecho igualitario a la libertad y, por lo tanto, al individualismo normativo en general. Quien somete a otro como un amo a sus esclavos no solo lesiona los derechos de la víctima, sino que niega el principio de individualismo normativo. En tal caso, nadie podría ser dueño de sí mismo. Por consiguiente, la reacción penal defiende el principio (y la seguridad) del derecho de libertad, pero atiende también por sí misma a los principios de libertad (en Kant: "respeta la humanidad en general").

Para ello, el Derecho penal se vale de las libertades políticas y de la legislación democrática, debido a dos razones al menos: la libertad como agencia, como dominio, solo es completa si

\footnotetext{
${ }^{3}$ Compárese, entre otros, con: PETTIT (2015), passim.

${ }^{4}$ VON DER PFORDTEN (2004), pp. 321-346.
} 
las restricciones necesarias para su habilitación y seguridad iguales y recíprocas son determinadas y justificadas por los propios afectados. Solo así las normas habilitantes de libertad que, a la vez, permiten la restricción general de la libertad se vuelven propias y no se entienden constituidas por un amo externo. Quienes tienen voz propia también deben poder expresarla en una legislación que sea vinculante para todos. Al mismo tiempo, el procedimiento de autolegislación del derecho penal garantiza que los ciudadanos puedan ponerse siempre en el lugar de los afectados por las leyes que restringen la libertad. En dicha operación, los ciudadanos deben considerar si aceptan las consecuencias adversas de aquellas leyes, aunque pasen del papel de colegislador al de persona afectada —el destinatario- No obstante, sigue abierta la cuestión de si este objetivo legítimo no puede y no debe alcanzarse por otro medio que no sea el del castigo público: la imposición deliberada e intencional de un mal (la causación de un dolor físico y mental). Sin embargo, esta cuestión permanecerá abierta aquí. ${ }^{5}$

A continuación, quisiera esbozar sucintamente y a grandes rasgos cómo ha cambiado hasta el día de hoy esta concepción central de la libertad y la función y significado de la protección penal de la libertad.

\section{3.}

Ya en 1797 Kant habla de "delitos públicos" como la falsificación de dinero y de letras de cambio cuya punibilidad considera necesaria y justificada. ${ }^{6}$ Estos se refieren a bienes públicos o colectivos como el funcionamiento del sistema monetario y del mercado garantizados por el Estado. A primera vista, no parece sencillo fundamentar la punibilidad de estas conductas en el marco de un Derecho penal que protege derechos de libertad individuales. No es casualidad que en 1834 Birnbaum acuse a Feuerbach de no poder fundamentar la protección penal de bienes, especialmente bienes públicos de interés general, como la eticidad [Sittlichkeit] y la religión, debido a su fijación en la protección penal de los derechos subjetivos (de libertad). ${ }^{7}$

Esta expansión de las tareas del Derecho penal más allá de la protección inmediata de la libertad individual puede leerse de dos maneras: la primera lectura es funcional a la libertad. El sistema económico amplía el ámbito de acción del individuo y, con ello, su ámbito de libertad. En esta dirección apuntan muchos autores que consideran no solo la vida y la integridad física, sino también la propiedad e incluso el sistema económico en su conjunto como requisitos previos para la existencia y la posibilidad de la libertad individual, y como medios para el incremento de la libertad. Simultáneamente, la expansión de la libertad va de la mano con una dependencia más intensa de los sistemas que garantizan las condiciones de existencia y las condiciones de posibilidad de la libertad, así como con sus propias racionalidades correspondientes. Se trata de la participación en tales sistemas (por ejemplo, en el papel del consumidor o del empleado en el sistema económico). Formulado en el lenguaje de la teoría de sistemas: estar incluido en tales sistemas significa para el individuo adaptarse a la racionalidad del sistema respectivo y a su lógica funcional, someterse de forma

\footnotetext{
${ }^{5}$ Compárese con GÜNTHER (2004) pp. 117-131, y GÜNTHER (2005), pp. 131-141.

${ }^{6}$ KANT (1797/1976), p. 452.

${ }^{7}$ BIRNBAUM (1834), pp. 149-194.
} 
adecuada no solo externamente, sino también organizarse internamente a través de las correspondientes disposiciones de autorreferencia y comportamiento.

En este contexto Foucault habla de subjetivación. ${ }^{8}$ Esta es la conocida dialéctica de ganancia y pérdida de libertad. Dentro de la ciencia penal, la teoría de protección de bienes jurídicos personales intenta justificar normativamente una conexión interna y necesaria entre la libertad individual y los bienes colectivos. También trata de defenderse como un imperativo de restricción contra todos los intentos de extender el derecho penal demasiado ligeramente a la protección de los bienes jurídicos públicos restantes.

La segunda lectura crítica del Derecho penal, entendido como protección de derechos subjetivos en nombre de la protección de bienes jurídicos, está orientada más bien a una perspectiva sistémico-funcionalista que a una centrada en la libertad $-\mathrm{o}$ funcional a la libertad - L La protección penal de bienes colectivos y las restricciones conexas de la libertad individual se justifican de manera utilitarista, al menos consecuencialista. Se afirma que existe un interés general en las consecuencias beneficiosas y útiles de la existencia y del uso sin obstáculos de estos bienes. Esto vale no solo para el mercado y el sistema económico, sino también para el propio Estado. Es cierto que este, por su parte, es un requisito previo para la existencia del mismo derecho de libertad, ya que sin él y su poder punitivo no sería posible protegerla y hacerla valer frente a ataques arbitrarios y transgresiones por parte de terceros.

La idea de que las personas se unan para formar una asociación voluntaria de personas vinculadas por ley ya sea en la forma de un contrato social o de una Constitución común, va acompañada de una percepción de que es necesario que la autoridad salvaguarde la ley contra su vulneración. Por eso Kant dice: "La mera idea de una Constitución estatal entre la gente trae consigo el concepto de justicia penal" (Kant, Rechtslehre, B 170). A este respecto, es la protección jurídico-penal del Estado, y sus instituciones en sí mismas, funcional a la libertad, porque sin el Estado no existiría el mismo derecho de libertad. Sin embargo, también es cierto aquí que la estricta funcionalidad ligada a la libertad siempre se ve amenazada por el propio interés del Estado en estabilizar su poder y aumentar su eficiencia, incluso en aquellos casos en que esto no está orientado funcionalmente a la libertad o solo lo es muy indirectamente - es decir, más allá de la alta traición y la garantía estatal de un sistema de dinero y crédito-.

\section{4.}

La lectura sistémico-funcionalista de la protección penal de los bienes jurídicos comienza a desplazar la lectura orientada hacia la libertad en la medida en que el Estado protege la libertad frente a los ataques de terceros no solo con su monopolio sobre el uso de la fuerza, sino que también garantiza las condiciones funcionales mínimas de los espacios de libertad colectivos y sistémicamente integrados con sus instituciones. Más bien, amplía el espectro de acciones. Este es el proceso que Max Weber, con la vista puesta en el desarrollo de finales del siglo XIX y principios del XX, ha descrito (críticamente) como "materialización del

\footnotetext{
${ }^{8}$ FOUCAULT (1986), capítulos IV y V.
} 


\section{Polít. Crim. Vol. 16, № 31 (Junio 2021), Doc. 1, pp. 437-455. [http://politcrim.com/wp-content/uploads/2021/07/Vol16N31D1.pdf]}

derecho formal". ${ }^{9}$ Esta expansión de la actividad estatal está, por supuesto, motivada normativamente por la experiencia de otra dialéctica de ganancia y pérdida de libertad que caracteriza a todo el siglo XIX, especialmente en su segunda mitad.

Con la industrialización y la expansión del capitalismo moderno se hace evidente el gran abismo que existe entre el derecho subjetivo general e igualitario de libertad, por un lado, y las condiciones socioeconómicas reales de su ejercicio individual, por otro. La extrema desigualdad socioeconómica significa para la mayoría de los sujetos de derecho de la sociedad civil que su derecho individual de libertad de acción no tiene ningún "valor" en el doble sentido de la palabra. Adicionalmente, las relaciones de poder asimétricas entre empresarios y capitalistas, por un lado, y trabajadores y "personas-económicamentedependientes", por otro, resulta ser un instrumento de dominación. Aquello sirve para justificar la desigualdad social a través de la subjetivación, es decir, asignando la responsabilidad del propio destino a la autonomía privada, al libre albedrío de la persona afectada.

El Estado social y de bienestar moderno trata de compensar esta desigualdad socioeconómica, disfuncional y destructiva de la libertad, a través de medidas estatales. Al mismo tiempo, el capitalismo moderno crece de forma dinámica y la división social del trabajo transforma la sociedad en una funcionalmente diferenciada con sistemas sociales autónomos. Además de la compensación de las desigualdades socioeconómicas, enfocada funcionalmente en la libertad, la integración en el sistema de subsistemas sociales autónomos adquiere cada vez un papel más importante.

Junto con esta expansión del Estado y la diferenciación funcional de las sociedades modernas, que se manifiesta desde hace más de un siglo y es impulsada por diferentes crisis históricas y catástrofes, tiene lugar una nueva dialéctica de ganancia y pérdida de libertad. Los sistemas de seguridad del Estado de bienestar, cuya existencia, crecimiento y funcionamiento dependen a su vez del crecimiento dinámico del sistema económico y de la diferenciación funcional de la sociedad en su conjunto, son los primeros en dar acceso a la mayoría de los sujetos jurídicos a un uso individual de la libertad que es efectivo en la práctica. Esto es sin duda un paso adelante en términos de libertad universal e igualitaria.

Sin embargo, con el constante incremento del Estado de bienestar burocrático se muestra también la otra cara de la moneda que amenaza la libertad: los individuos dependen cada vez más de las directrices de la administración del Estado de bienestar, el que interviene en la planificación y conducción de su vida para que puedan cumplirse los requisitos legales de una biografía laboral y de pensiones normalizada. La inclusión del individuo qua diferentes roles sociales en los diversos sistemas funcionales requiere esfuerzos de adaptación cada vez mayores y más intensos por parte del propio individuo. Esto es válido especialmente para la inclusión en el sistema económico. Con ello se modifica también el individualismo normativo que va de la mano con el principio de derechos subjetivos de libertad (generales e iguales) - más o menos distante, como siempre lo ha estado, de la realidad social—. La libertad individual se vuelve por sí misma más funcional a la integración social y sistémica

\footnotetext{
${ }^{9}$ WEBER (1976), capítulo VII, § 1. p. 397.
} 
de las sociedades modernas. A partir de esto, Foucault arriba a la radical conclusión de que la libertad se entiende - en sí misma- como una técnica de subjetivación. Con su ayuda, la población contribuye a aumentar su crecimiento y bienestar por medio de la autooptimización y la autoactivación —el tránsito de un poder disciplinario externamente represivo a un biopoder que promueve la vida y funciona a través de la actividad de los propios sujetos-.

Por lo tanto, sería también erróneo interpretar el impulso de modernización de los Estados de bienestar funcionalmente diferenciados solo como el resultado de una asistencia paternalista y, en última instancia, promovido por las clases dirigentes. En gran medida, también son impulsados por los ciudadanos afectados y sus propias demandas políticas. Estos se guían por una concepción de la libertad que ya no la ve principalmente como la articulación y el desempeño de la agencia y la responsabilidad individuales, sino más bien como una oportunidad para participar activamente en las posibilidades de acción que ofrecen los sistemas sociales y las formas de vida organizadas colectivamente.

Esto se torna evidente de forma relativamente temprana en la transición de la teoría de la voluntad a la teoría de intereses en la comprensión del derecho subjetivo. Tal y como reconoce Ihering desde un principio: se trata de intereses socialmente atribuidos que el individuo tiene solo por interés (o ventaja) general. Por supuesto que esto no significa que en el micro-nivel del comportamiento social no habría más opciones de elección para los individuos, esto es, que se cerrara la experiencia primaria de la libertad individual de elección. Esto concierne solo a los sistemas totalitarios con un pequeño margen de acción individual y una gran variedad de directrices de acción organizada. Con todo, el significado de la libertad individual se desplaza cada vez más hacia la posibilidad de participación social, al acceso a los sistemas sociales y a los bienes que estos producen y proporcionan. En este sentido, la libertad individual de elección se reduce en gran medida al consumo de bienes ofrecidos por el mercado.

Es solo cuestión de tiempo para que el interés por la libertad pase de la articulación y el desempeño de la autonomía individual, a asegurar el acceso a los sistemas sociales y garantizar su existencia y funcionamiento. Por eso la lectura sistémico-funcional de las condiciones sociales previas de la libertad individual no encuentra contradicción casi en ningún lugar. Para la comprensión de la libertad como una posibilidad de acceso, la funcionalidad de la libertad se reduce a la funcionalidad del sistema.

\section{5.}

¿Qué función y significado tiene el Derecho penal dentro de este paradigma de Estado de bienestar? No solo puede observarse una expansión sin precedentes del derecho penal en casi todas las esferas de la acción social. El número de bienes protegidos, especialmente los colectivos, aumenta considerablemente. La "funcionalidad" [Funktionsfähigkeit] de las distintas esferas individuales de acción pertinentes se convierte en la justificación de política criminal decisiva para las intervenciones del derecho penal. Esto es particularmente cierto en la esfera del derecho penal económico, donde se protege penalmente el funcionamiento de diversos mercados, la competencia y las modalidades individuales de transacciones de pago. Sin embargo, el medio ambiente y otros bienes colectivos también se convierten en bienes jurídicos protegidos por el derecho penal. 
A menudo, la cuestión de las posibilidades alternativas de regulación del derecho penal que son más respetuosas de la libertad, es decir, la cuestión de la ultima ratio, que por su parte es funcional a la libertad, ya no se plantea en absoluto o solo se hace de forma retórica, para ser respondida inmediatamente de manera afirmativa.

El paradigma del Estado de bienestar se expresa en la posición prominente de la prevención como una finalidad de la pena, especialmente la prevención especial a través de la resocialización. La dependencia de la libertad individual de las condiciones sociales y colectivas previas significa que la respuesta del Derecho penal ya no está vinculada primariamente a la responsabilidad individual del sujeto, sino más bien a las propias condiciones sociales o a la interrelación entre el individuo y la sociedad, es decir, a la (fallida, perturbada) socialización e integración social.

Por lo tanto, la resocialización significa — sobre todo- habilitación para participar, para percibir individualmente las condiciones sociales de libertad. Con esta comprensión se relativiza el individualismo normativo del siglo XIX, al menos en el sentido de que ahora se presta mayor atención a la dependencia del individuo y su libertad de las condiciones sociales de vida y el orden normativo según el cual se distribuyen los bienes y oportunidades. En consecuencia, las reformas sociales, la compensación social y la reducción de la desigualdad social también se convierten en un elemento importante de la política criminal. La política del Estado de bienestar también contribuiría a minimizar el comportamiento criminal eliminando sus causas socio-estructurales. La corresponsabilidad social del delito se sitúa junto a la responsabilidad individual del autor penal.

El Derecho penal del paradigma del Estado de bienestar también tiene por objeto alcanzar un efecto preventivo general. Una línea de argumentación existente desde von Liszt supone que la pena sirve para proteger a la sociedad, sus bienes colectivos y los intereses generales. La protección de la sociedad también significa la protección de la nación en una contienda global. Esto es especialmente patente en la obra de von Liszt. Allí donde se pierde la referencia a la libertad o incluso se niega políticamente de forma consciente, puede tener lugar una prioridad de los deberes del individuo para con la comunidad y el Estado sobre los derechos (de libertad) individuales. La comisión de un delito aparece entonces primariamente como una violación del deber de lealtad del individuo hacia la comunidad. Pero incluso cuando la referencia a la libertad se conserva o se restablece, al menos indirectamente, después de la catástrofe de un régimen totalitario, la libertad sigue estando mediada por sus relaciones sistémicas. Esto difícilmente puede evitarse porque la acelerada modernización técnico-capitalista conlleva un inmenso aumento de la complejidad de la sociedad. En última instancia, supera las fronteras nacionales, como puede reconocerse en los procesos de globalización del sistema económico.

Este incremento de la complejidad conduce nuevamente a una considerable expansión del ámbito de la libertad individual. Con el gran crecimiento y la rápida aceleración de las innovaciones técnicas, el ámbito de acción de cada individuo se amplía, y con la economización de su producción y distribución, se hace accesible a la gran mayoría de las poblaciones de los Estados de bienestar industrializados. Esto comienza con la movilidad 
individual a través del tren, el auto y el avión, entre otras innovaciones que hacen la vida cotidiana más sencilla. El mejoramiento de los servicios de salud y de la medicina son otros ejemplos importantes y, más recientemente, el inmenso aumento de las posibilidades de comunicación mediante las tecnologías digitales. El incremento de la libertad y el aumento de la prosperidad van de la mano. Al mismo tiempo, empero, se hace evidente que el entrelazamiento de la libertad con sus requisitos previos técnicos e infraestructurales se intensifica considerablemente. Esto puede llegar tan lejos que a algunos les parece que la técnica se ha apoderado del ser humano, como si la libertad individual fuera solo una farsa y una mentira, mientras que en realidad el pensamiento, el sentimiento y las acciones están determinados por la técnica. Esta impresión se ve reforzada por el hecho de que la técnica (y la economía) son presentados como fenómenos presuntamente apolíticos, cuya racionalidad interna obligaría a tomar decisiones y medidas necesarias que no parecen ser políticamente criticables y negociables, es decir, que no están a libre disposición de una sociedad que se autodetermina por leyes de libertad igualitaria.

La intensificación del entrelazamiento de la libertad individual con sus requisitos previos técnicos y económicos tiene como consecuencia que los riesgos aumenten considerablemente, especialmente en contextos de acción mediados técnicamente. ${ }^{10}$ Los accidentes ferroviarios, el derrumbe de gimnasios deportivos y fábricas, las graves alteraciones de instalaciones técnicas, como las centrales nucleares, que implican peligros considerables para un número incalculable de personas, así como también los numerosos accidentes más pequeños que admiten peligros más o menos graves y daños reales a las personas en el sector médico, farmacéutico y en el tráfico rodado, no suponen actos delictivos deliberados de un delincuente malintencionado, sino más bien se refieren a violaciones involuntarias de normas de conducta y obligaciones, que conducen a peligros abstractos o concretos, o bien, directamente a perjuicios. Por consiguiente, los sistemas complejos requieren un gran número de deberes de comportamiento para asegurar su funcionalidad y evitar peligros y daños. Estas cubren toda la sociedad como una red bien tejida; solo aquellos que se someten a esta red hacen uso de su libertad de una manera libre o con mínimos riesgos. $^{11}$

La libertad individual sin obligaciones de comportamiento que la acompañen se transforma en un riesgo — la libertad por sí misma se convierte en un peligro y en una amenaza-. Así, no se puede tener libertad sin obligaciones. Por esta razón, el paradigma de Derecho penal del Estado de bienestar en las sociedades modernas también incluye delitos de peligro abstracto y concreto, así como una mayor anticipación de la punibilidad de ciertas conductas.

Esto conduce a un cambio de paradigma del Derecho penal. De la vulneración de derechos (o bienes jurídicos) a la violación de obligaciones, pero esta vez no en el sentido de un Derecho penal totalitario de omisión dirigido a la lucha por la supervivencia de una comunidad nacional que comparte un mismo destino. Se trata más bien de un de derecho penal de obligaciones cuyo objeto es organizar diferentes esferas de acción riesgosas y mediadas por la técnica. Pero que son socialmente deseables, ventajosas y mejoran el bienestar general. De esta manera se pretende evitar daños a la vida, la integridad física y a

\footnotetext{
${ }^{10}$ PRITTWITZ (1993), passim.

${ }^{11}$ CHEN (2016); BUNG (2016), p. 342.
} 
la propiedad. El caso ejemplar, que también tiene una función de construcción conceptual y teórica para los estudiosos del Derecho penal, es el delito culposo, en forma de delito por omisión culposo. ${ }^{12}$ El guardagujas que, distraído por un juego de computador, olvida activar a tiempo una señal de detención para un tren puede desencadenar un desastre. En vista de las complejas cadenas de acción mediadas técnica y económicamente, en las que participan numerosas personas, la cuestión de cómo puede atribuirse una amenaza o una lesión de bienes jurídicos como la "obra" de una persona responsable se convierte en una pregunta central.

Con la sociedad de riesgo moderna, la seguridad se vuelve el objeto de protección más importante del Derecho penal. Por sí misma, implica una peculiar y reflexiva mejora del Estado de derecho de carácter liberal. En realidad, el Derecho penal estatal debió haber garantizado siempre la seguridad de los derechos, especialmente los de libertad (compárese más arriba con la cita de Feuerbach). A este respecto, la seguridad es idéntica al derecho penal del Estado; su propósito es asegurar el derecho general e igualitario de libertad. ${ }^{13}$ En este sentido, el actual discurso acerca de un "deber de proteger" o una "responsabilidad de proteger" por parte del Estado en relación con los derechos básicos y humanos especialmente el derecho de libertad-, solo habla de una trivialidad. Sin embargo, si la seguridad misma adquiere de nuevo la condición de bien jurídico necesitado de protección penal, entra en competencia con la libertad. En el peor de los casos, se configura un juego de suma cero: cuanta más libertad, menos seguridad $-\mathrm{y}$ viceversa-. Pero dado que la seguridad es un bien que nunca se satura, el ganador en este juego está claro desde un principio. ${ }^{14}$ Cada medida orientada a mejorar la seguridad revela nuevos vacíos a partir de los cuales surgen otros riesgos que exigen a su vez más seguridad.

\section{6.}

El anhelo de mayor seguridad es alimentado por otra consecuencia de la creciente libertad individual. Se revela la conocida relación entre libertad individual y sus requisitos sociales previos de manera particularmente manifiesta. La Modernidad adopta rasgos reflexivos. ${ }^{15} \mathrm{La}$ modelación de la propia vida se encuentra en manos del individuo, aunque en muchos casos se limite a la elección entre ofertas preestablecidas social y económicamente. La formación del yo, de la identidad individual y, con ello, del estilo y proyección de la vida son más subjetivos que antes, al depender de las decisiones del individuo. Su inclusión en los contextos locales, comunitarios y sociales es más débil. Qué profesión se ejerce y cuánto tiempo se ocupa en ella, qué compañero o compañera se escoge, cuándo se tendrá una familia y qué forma de familia, a quién y cómo se desea, dónde y cómo se vive, son preguntas que cada persona debe responder por sí misma. Con los rasgos reflexivos de la Modernidad las respuestas no están determinadas esencialmente por la clase, el género, la pertenencia a comunidades religiosas y étnicas. Las sociedades modernas se caracterizan por una pluralidad de estilos de vida y de identidades que conforman al individuo, pero que no lo determinan, sino que son escogidos conscientemente.

\footnotetext{
${ }^{12}$ GÜNTHER (1995), pp. 445-460.

13 GIERHAKE (2013), p. 112 y ss.

${ }^{14}$ FRANKENBERG (2010), passim.

${ }^{15}$ Clásicos a estas alturas: BECK (1986), passim y GIDDENS (1991), passim.
} 
Esto también se aplica a las comunidades a las que una persona pertenece: este proceso de individualización aumenta, al mismo tiempo, la dependencia de cada sujeto de los requisitos tecnológicos, económicos y sociales que se relacionan con una identidad reflexiva y un estilo de vida. Debido a que estos requisitos previos deben ser creados, reproducidos y preservados constantemente, son altamente susceptibles a fallar. La modernización reflexiva, la individualización y el pluralismo van de la mano con una sociedad capitalista liberal de mercado cuya dinámica de crecimiento es producida por la correspondiente infraestructura. Las crisis económicas y financieras, pero también los procesos de crecimiento económico que solo benefician a un pequeño estrato de la sociedad y, por lo tanto, profundizan la desigualdad social mucho más allá del nivel que permitiría incluso a los más desfavorecidos llevar una vida mejor, amenazan, además de la infraestructura, directamente la libertad individual que depende de esta.

La libertad, por lo tanto, lleva aparejada la experiencia de una mayor vulnerabilidad individual - y la experiencia de esta vulnerabilidad aumenta a su vez la necesidad de seguridad - La independencia de los demás alcanzada a través de la individualización muestra su reverso cuando el individuo se enfrenta al riesgo de quedarse solo. La individualización y la pluralización por sí mismas aumentan esta sensibilidad por la vulnerabilidad, incluso entre aquellos cuya situación socioeconómica es relativamente privilegiada porque la solidaridad concreta prácticamente solo puede esperarse en virtud de la pertenencia a un modo de vida particular y no a una comunidad relativamente homogénea. ${ }^{16}$ Sin embargo, quienes arriesgan perder sus relaciones y redes sociales, especialmente bajo la presión socioeconómica de la precarización gradual, y quienes se retiran de la sociedad a causa del miedo al descenso social, solo contabilizan pérdidas en sus balanzas de vida y no ganancias de libertad.

Estos temores se mantienen difusos en la medida que se dirijan hacia fuerzas opacas, incontrolables y funestas; que tal vez operan a nivel global. La criminalidad puede dar a estos temores un destinatario más concreto; en cierto modo, aglutina la propia vulnerabilidad en una forma ajena. El crimen se convierte en una pantalla de proyección de todos los miedos que resultan del aumento de la dependencia y de la vulnerabilidad del sujeto. Con cada delito, especialmente cuando se dirige contra la vida y la integridad física o la autodeterminación sexual, el equilibrio entre la conciencia de la propia vulnerabilidad y la confianza en la integridad del entorno social corre el riesgo de desbalancearse. Esto afecta incluso a quienes no están involucrados en la comisión del delito.

Un síntoma de lo anterior es la creciente tendencia a identificarse con las víctimas de delitos cuyos destinos son difundidos por los medios de comunicación. ${ }^{17}$ De esta manera emerge una especie de comunidad negativa entre quienes utilizan las narrativas de las víctimas para dar testimonio de la existencia de su vulnerabilidad; una comunidad de vulnerabilidad compartida. Así, crean una solidaridad selectiva que se expresa no solo en una sensación de inseguridad compartida, sino que también en la atribución de características negativas a grupos de población conformados por personas divergentes o, más concretamente, personas

\footnotetext{
${ }^{16}$ Para la reciente discusión acerca del concepto de vulnerabilidad, véase solamente: MACKENZIE et. al. (2014), passim.

${ }^{17}$ GARLAND (2008), p. 355; GÜNTHER (2013), pp. 185-248.
} 
sospechosas de ser potenciales fuentes de delitos. El foco de la atención pública y de la política criminal ya no es la lesión del derecho o del bien jurídico, esto es, la comprensión del delito como el ataque más grave a la libertad como derecho humano original y único. Ahora se encuentra, en cambio, en la lesión concreta e individual. Para la verdadera víctima del delito la lesión concreta se convierte en un signo de la destrucción de la confianza social y en la afirmación brutal de su propia vulnerabilidad. Este significado de la lesión individual tiene consecuencias mentales reales que pueden manifestarse en traumas de larga duración. Los relatos de las víctimas se consideran públicamente como casos ejemplares para un proceso de formación de opinión política y de toma de decisiones, que tiene por objeto proteger a comunidades o formas de vida especiales de posibles perjuicios; para promover una política de respeto hacia lo especial, lo cercano, lo presente. ${ }^{18}$ El Derecho penal y el sistema de justicia penal serán entonces más exigentes en cuanto a la demostración de empatía con la víctima y a la adopción de medidas más estrictas contra el autor.

Este aspecto de la dialéctica de ganancia y pérdida de libertad explicaría por qué la necesidad de seguridad de la propia forma de vida [Lebensform] se hace mayor que la aspiración de una protección igualitaria y general del derecho de libertad. Al fin y al cabo, no se trata de la libertad de acción individual como principio general del derecho, sino solo de ciertas formas de uso compartido de la libertad, que ya no son transparentes para los actores como tales.

Según Rahel Jaeggi, una forma de vida puede entenderse como un conjunto de "conexiones de prácticas y orientaciones y órdenes de comportamiento social" que tienen una cierta duración, que están constituidas por creencias, actitudes y un habitus, y se manifiestan en "instituciones, símbolos y artefactos". ${ }^{19}$ El Derecho penal protege entonces diversos contextos de prácticas compartidas y los bienes necesarios para la superación de tareas específicas de las formas de vida, así como los requisitos previos de infraestructura para su reproducción. Resumido brevemente: el fin del Derecho penal se convierte en la protección de la forma de vida. Las normas inherentes a las prácticas compartidas de una forma de vida están solo vagamente conectadas con la libertad, entendida como derecho general e igualitario.

Sin embargo, la protección de las formas de vida no significa que todas las formas de vida se consideren igualmente dignas de protección. Esto solo se aplica a aquellas que se muevan dentro del espectro de las sociedades modernas, individualistas, pluralistas y liberales de mercado, que se apoyan sistemáticamente en la diferenciación social y se caracterizan socialmente por una comprensión de la libertad que consiste sobre todo en la autorrealización individual y en el consumo individual de bienes sobre la base de valores compartidos. Puede existir controversia sobre qué formas de vida pertenecen a este espectro y cuáles no pertenecen o han dejado de pertenecer. Y también puede existir sobre la interpretación apropiada de las prácticas, hábitos y creencias dentro de una misma forma de vida. Las preguntas: qué forma de vida se reconoce, de qué manera y en qué medida también están sujetas a cambios históricos causados por diversos factores. Por ejemplo, hay casos en los que las uniones de parejas del mismo sexo pueden ser reconocidas, pero el matrimonio entre ellas no lo es; los prejuicios homofóbicos pueden resurgir y conducir a una nueva

\footnotetext{
${ }^{18}$ ROSANVALLON (2010), p. 233.

${ }^{19}$ JAEGGI (2014), p. 89.
} 
discriminación. El único factor decisivo en este caso es que la necesidad de protección penal solo está vinculada a la aceptación mayoritaria de una forma de vida y no al derecho general e igualitario de libertad. Es esa aceptación la que justifica la protección penal de ciertos bienes como bienes jurídicos. Ya no es la funcionalidad que se refiere a la libertad lo importante, sino su funcionalidad de forma de vida.

Cuando se trata principalmente de la protección de formas de vida en atención a su vulnerabilidad en las sociedades modernas, diferenciadas, individualistas y pluralistas, la seguridad se convierte en un objeto central de protección. Por ello, no se trata solo del conjunto básico de bienes jurídicos que es esencial para un derecho de libertad general e igualitario, sino también de todos los bienes jurídicos colectivos que son importantes para la forma de vida. La protección de formas de vida vulnerables también requiere el control y rechazo de riesgos y peligros. Por esta razón, los delitos de peligro abstracto y concreto se consideran tan necesarios como, en general, una anticipación de gran alcance de la punibilidad de las conductas. No obstante, el Derecho penal como protector de formas de vida significa también que las formas de vida desviadas del consenso mayoritario se consideran una fuente potencial de peligro que debe ser vigilada. Por esta razón, las prácticas, hábitos y actitudes desviadas están bajo el escrutinio de la observación, el control, la prevención y la atención estatal (y, cada vez más también, privada).

Esto lleva a un sorprendente hallazgo desde la perspectiva de un Derecho penal liberal: la pérdida de libertad causada por el derecho penal de seguridad moderno es —en gran medida - acogida, aceptada e incluso exigida políticamente por la mayoría de la ciudadanía. Nadie experimentará personalmente la pérdida de libertad en términos concretos siempre y cuando se ajuste a las prácticas, hábitos y actitudes que se ubican dentro del espectro de formas de vida aceptadas por la mayoría. Es decir, dentro de la normalidad. Por lo demás, mientras tales prácticas, hábitos y actitudes sean seguidas a muy pocas personas les molestará ser observados y controlados. Pues, como contempla el dicho: "no hay nada que ocultar". Con otras palabras, uno sabe que está en el lado seguro de la normalidad.

Pero quien no pertenezca a esta normalidad referida a la mayoría de las formas de vida casualmente aceptadas, quien se desvíe de ella a través de sus acciones, debe asumir que padecerá una verdadera pérdida de libertad. Frente a él, se rescinde el contrato social por una legislación política que ya no sigue los principios de reciprocidad y generalidad. No obstante, esto cuestiona una condición esencial que fue explicada al principio. La mayoría legislativa ya no necesita hacer suya la perspectiva de la minoría afectada por la ley para averiguar si, en caso de estar en el lugar de la minoría desfavorecida, aceptaría aún esa ley. Con las distinciones entre desviación y normalidad, entre lo propio y lo ajeno, el legislador excluye a las personas que se encuentran en el lado negativo del cambio de perspectiva. Las restricciones de libertad establecidas mediante un Derecho penal preventivo y un Derecho procesal penal equipado con métodos policiales ya no son temidas por la mayoría de la ciudadanía. Ellos saben que siempre se encontrarán del lado positivo del cambio de perspectiva. Las consecuencias adversas del control de libertad, la pérdida real de libertad a través de medidas preventivas o sanciones penales represivas solo se producirán en los demás - la minoría disidente — . Las formas de vida aceptadas por la mayoría se atrincheran y confeccionan leyes solo para ellos mismos, para su supervivencia en un entorno percibido como extraño y hostil. En términos concretos: las modernas técnicas de vigilancia — la 
vigilancia policial, la intervención secreta de casas particulares, el espionaje de computadores y la retención de datos - suponen intervenciones masivas de la libertad individual que ya no indignan a nadie que esté en el lado seguro de la normalidad, pese a que su libertad individual también sea observada. El resto está compuesto de enemigos potenciales o reales. Su libertad puede ser restringida en la medida necesaria para asegurar la forma de vida particular y su concepto de libertad que la mayoría ha aceptado colectivamente.

\section{7.}

Esta estructura de argumentación se ve reforzada por los peligros del terrorismo internacional. Aquí también se trata explícitamente de la defensa de la propia forma de vida contra extranjeros y enemigos. Los ataques terroristas revelan dramáticamente la vulnerabilidad de la propia forma de vida. El aspecto preventivo del Derecho penal se extiende más todavía. Una característica importante es — de nuevo- la anticipación de la punibilidad mucho más atrás del comienzo de una puesta en peligro a un bien jurídico. Esto puede verse, por ejemplo, en el §89a del Código Penal alemán que fue reformado en 2009/2015. Estas modificaciones tipifican como delito la "preparación de un acto grave de violencia que ponga en peligro a la seguridad del Estado". Se trata de actos preparatorios en el momento previo a una lesión del bien jurídico. Con esto se difumina el límite entre el comienzo de la tentativa — punible — y el acto preparatorio — no punible—. El §89 a párrafo 2a va particularmente lejos al contemplar una hipótesis de delito de emprendimiento: aquí el hecho ya está "consumado" cuando alguien realiza un viaje a otro Estado con el propósito de cometer delitos graves para los cuales fue instruido y que pongan en peligro dicho Estado. La persecución penal forma una "asociación de investigación funcional" con la policía, los servicios secretos y el ejército. Todas las medidas de este tipo se coordinan también a nivel internacional, como lo demuestra, por ejemplo, la reciente propuesta de directiva del Consejo y el Parlamento Europeo sobre la lucha contra el terrorismo de 2015/16 (COM (2015) 625 final). Un ejemplo de medidas encubiertas es la vigilancia mundial del tráfico de teléfonos móviles y datos por parte de la autoridad estadounidense, la Agencia de Seguridad Nacional (NSA). Mientras funcione la estructura de argumentación antes explicada, esto es, que la mayoría no espere ver sus libertades restringidas por las medidas y operaciones preventivas, no se percibirá entonces como algo ilegítimo.

Paralelamente, se advierte un interés decreciente en la libertad individual como derecho universal e igualitario. El uso de la libertad aparece generalmente como riesgoso. Y en la medida en que ciertas formas y maneras de uso de la libertad sean idénticas a la forma de vida particular de los Estados de bienestar modernos, se defenderá esta forma de vida y no la libertad como tal. En tal sentido, las intervenciones estatales en la libertad ya no aparecen como amenazantes si solo garantizan la seguridad de la forma de vida. Pero ¿qué queda realmente de la libertad si permitimos que nuestro comportamiento sea controlado tanto extensiva como intensivamente? Es posible que se haya perdido el sentido para el momento de la libertad. Momento que se identifica con el concepto de agencia, como capacidad de acción. El momento de poder efectuar un comienzo [einen Anfang machen können], de lo espontáneo, de lo sorprendente, de los que se desvían de la normalidad.

Con la mirada puesta en los otros, la libertad aparece, en gran medida, como un riesgo. Con la mirada puesta en uno mismo, aparece como una demanda excesiva. Tal vez, la mayor 
amenaza a la libertad de acción individual como principio jurídico no proviene solo de los sistemas estatales y privados de vigilancia electrónica u otras restricciones del derecho (penal) de seguridad. Posiblemente el origen sea interno, de un progresivo desinterés por la libertad. Michel Houellebecq expresó esta amenaza en su novela "Sumisión". Este desinterés lo sintetiza su protagonista masculino, quien lleva una vida triste en la que ha perdido todo el sentido de su propio poder de acción. La vivencia es tan completa y exhaustiva que ni siquiera logra llevar a cabo el suicidio planeado. Una vida sin autonomía, una vida de servidumbre voluntaria y dependencia de patrones asistenciales parece ser la única salida que aún vale la pena. El protagonista arriba a este reconocimiento, por así decirlo, liberado del peso de la libertad cuando observa a las esposas veladas de un hombre musulmán en el tren: "Evidentemente perdían autonomía [las mujeres], pero fuck autonomy, por mi parte estaba obligado a reconocer que había renunciado con facilidad, e incluso con verdadero alivio, a cualquier responsabilidad de orden profesional o intelectual [... ${ }^{\prime 20}$ Aunque esta novela distópica describe un futuro lejano (y esperemos que nunca llegue a serlo), las crisis constitucionales en Europa y la creciente simpatía por los gobiernos autoritarios tanto en Europa como en EE.UU. muestran que la libertad individual y política está perdiendo su significado. La protección y la seguridad de la propia forma de vida, la agresiva autodefensa de la supuesta identidad homogénea de una comunidad contra extraños y enemigos se valoran más que la libertad.

Ahora, por supuesto, sería una jugada demasiado fácil acuñar un reproche moral a partir de esto. Tal cuestión correspondería a la limitada técnica de argumentación neoliberal: acusar a los verdaderos perdedores de la globalización y a los que temen pertenecer a ella de estar sobrecargados de libertad y atribuirles la condición de perdedores como responsabilidad propia. Es más probable que el peligro provenga de quienes se aprovechan de las preocupaciones por la vulnerabilidad y se benefician de los regímenes públicos y privados de libertad controlada. En su discurso de la ceremonia de entrega del Premio Schirrmacher 2016, Houellebecq citó a un autor que ya había advertido en 1840 el despotismo que surgía de la propia democracia: ${ }^{21}$ por encima de los ciudadanos cada vez más aislados, preocupados solo de su propio bienestar, se alza "un poder impetuoso y condescendiente, que es el único que garantiza que sus placeres estén asegurados y su destino sea vigilado. Es ilimitado, minucioso, regular, preventivo y suave. [...] Le gusta trabajar por su bienestar (es decir, el del ciudadano); pero quiere ser su único tutor y juez; se ocupa de su seguridad, mide y asegura sus necesidades, facilita sus placeres, dirige sus negocios más importantes, gestiona su industria, arregla sus herencias, comparte su patrimonio; ¿no podría también aliviarles de la preocupación por la reflexión y el trabajo de la vida?".22

Cuando el poder condescendiente y caritativo realiza esto priva de su sustrato al sentido de la libertad: "De este modo, [el poder] hace que el uso del libre albedrío sea menos valioso cada día que pasa; limita el ejercicio de la voluntad a un área pequeña y, finalmente, despoja a cada ciudadano del derecho a disponer de sí mismo [...]", hasta que el pueblo "se transforma

\footnotetext{
${ }^{20}$ Citado desde la versión en español: HOUELLEBECQ (2015), Sumisión (Barcelona, Anagrama), p. 215. En el original: HOUELLEBECQ (2015), p. 202 y s.

${ }^{21}$ HOUELLEBECQ (2016), p. 9.

22 de TOCQUEVILLE (1987), p. 463 y s.
} 


\section{Polít. Crim. Vol. 16, No 31 (Junio 2021), Doc. 1, pp. 437-455. [http://politcrim.com/wp-content/uploads/2021/07/Vol16N31D1.pdf]}

en un rebaño de animales temerosos e industriosos, cuyo pastor es el gobierno". ${ }^{23}$ Cuando Houellebecq dice que estos pasajes contienen "prácticamente toda mi obra", está siguiendo el mismo temor de Tocqueville. El temor de que este despotismo surge de una disminución de las virtudes y costumbres democráticas. Pero ambos pasan por alto el hecho de que el poder condescendiente y caritativo no se crea de la nada, sino que está latente siempre y aumenta hasta su manifestación efectiva si puede utilizar la preocupación por la seguridad en su propio beneficio. Su primer objetivo es redirigir la idea de libertad universal e igualitaria al interés por proteger la propia forma de vida. Cuando se asegura la forma de vida se pierde el interés por la libertad. No es coincidencia que en estos círculos de poder la Ilustración también sea despreciada. En consecuencia, el derecho penal ilustrado también está acabado. El derecho penal protege entonces a la manada de animales temerosos e industriosos de las irritaciones causadas por los pocos "espíritus más originales y almas más fuertes" 24 que hacen un uso soberano de su libertad.

${ }^{23}$ de TOCQUEVILLE (1987), p. 464.

${ }^{24}$ DE TOCQUEVILLE (1987), p. 464. 


\section{Bibliografía citada}

BECK, Ulrich (1986): Risikogesellschaft (Fráncfort del Meno, Suhrkamp).

BIRNBAUM, Johann (1834): "Über das Erfordernis einer Rechtsverletzung zum Begriffe des Verbrechens", en: KLEIN, Ernst Ferdinand y KLEINSCHROD, Gallus Aloys (ed.), Archiv des Criminalrechts, Neue Folge, segunda parte, año 1834 (Halle, Hemmerde \& Schwetschke) pp. 149-194.

BUNG, Jochen (2016): "Fünf Grundprobleme des heutigen Strafrechts", en: ZIS (11. año), pp. 340-344.

CHEN, Chun-Wie (2016): Gefährdungsvorsatz im modernen Strafrecht (Fráncfort del Meno/Berna, Peter Lang).

FEUERBACH, Paul Johann Anslem (1801): Lehrbuch des gemeinen in Deutschland geltenden Peinlichen Rechts (Gießen, Heyer).

FOUCAULT, Michel (1986): Sexualität und Wahrheit (Fráncfort del Meno Suhrkamp) Tomo I.

FRANKENBERG, Günter (2010): Staatstechnik. Perspektiven auf Rechtsstaat und Ausnahmezustand (Fráncfort del Meno, Suhrkamp).

GARLAND, David (2008): Die Kultur der Kontrolle (Fráncfort del Meno/Nueva York, Campus).

GIDDENS, Anthony (1991): Modernity and Self-Identity. Self and Society in the Late Modern Age (Cambridge, Blackwell Publishers).

GIERHAKE, Katrin (2013): Der Zusammenhang von Freiheit, Sicherheit und Strafe im Recht. Eine Untersuchung $\mathrm{zu}$ den Grundlagen und Kriterien legitimer Terrorismusprävention (Berlín, Duncker \& Humblot).

GÜNTHER, Klaus (1995): "Von der Rechts- zur Pflichtverletzung. Ein „Paradigmawechsel“ im Strafrecht?", en: Institut für Kriminalwissenschaften der Johann Wolfgang Goethe-Universität, Vom unmöglichen Zustand des Strafrechts (Fráncfort del Meno/Berna, Peter Lang), pp. 445-460.

GÜNTHER, Klaus (2004): "Kritik der Strafe I", en: WestEnd - Neue Zeitschrift für Sozialforschung (2004), pp. 117-131.

GÜNTHER, Klaus (2005): "Kritik der Strafe II", en: WestEnd - Neue Zeitschrift für Sozialforschung (2005), pp. $131-141$.

GÜNTHER, Klaus (2013): “Ein Modell legitimen Scheiterns. Der Kampf um Anerkennung als Opfer”, en: HONNETH, Axel; LINDEMANN, Ophelia y VOSWINKEL, Stephan (ed.), Strukturwandel der Anerkennung (Fráncfort del Meno/Nueva York, Campus), pp. $185-248$.

HOUELLEBECQ, Michel (2015): Unterwerfung (Colonia, DuMont).

HOUELLEBECQ, Michel (2015): Sumisión (Trad. Joan Riambau Möller, Barcelona, Anagrama).

HOUELLEBECQ, Michel (2016); "Ich bin ein halber Prophet", en: FAZ Nr. 226 de 27.9.2016

JAEGGI, Rahel (2014): Kritik von Lebensformen (Berlín, Suhrkamp).

KANT, Immanuel (1975): Metaphysik der Sitten, Rechtslehre 1797/1798, Werke Tomo IV, ed. Weischedel, (Darmstadt).

KANT, Immanuel (2008): La Metafísica de las Costumbres (Trad. Adela Cortina y Jesús Conill, Madrid, Tecnos). 
MACKENZIE, Catriona; ROGERS, Wendy y DODDS Susan (2014): Vulnerability. New Essays in Ethics and Feminist Philosophy (Oxford, Oxford University Press).

PETTIT, Philip (2015): Gerechte Freiheit: Ein moralischer Kompass für eine komplexe Welt (Berlín, Suhrkamp).

VON DER PFORDTEN, Dietmar (2004): "Normativer Individualismus”, en: Zeitschrift für philosophische Forschung (vol. 58), pp. 321-346.

PRITTWITZ, Cornelius (1993): Strafecht und Risiko (Vittorio Klostermann, Fráncfort del Meno).

ROSANVALLON, Pierre (2010): Demokratische Legitimität. Unparteilichkeit Reflexivität - Nähe (Hamburgo, Hamburger Edition).

DE TOCQUEVILLE, Alexis (1987): Über die Demokratie in Amerika, edición alemana (Zúrich, Manesse), Tomo II.

WEBER, Max (1976): Rechtssoziologie, en: Wirtschaft und Gesellschaft, eds. Winckelmann, $5^{\circ}$ ed. (Tubinga, Mohr). 